\title{
Prevalence of external genital abnormalities among primary school pupils in Ekiti State, Nigeria
} \author{
Ajayi Akande Oladimeji ${ }^{3}$, Ajayi Ebenezer Adekunle ${ }^{3}$ \\ ${ }^{1}$ Department of Surgery, Ekiti State University, Ado-Ekiti, Nigeria \\ ${ }^{2}$ Department of Community Medicine, Ekiti State University, Ado-Ekiti, Nigeria \\ ${ }^{3}$ Department of Medicine, Ekiti State University, Ado-Ekiti, Nigeria
}

Adegun Patrick Temi ${ }^{1,}$, , Bamidele James Olusegun ${ }^{2}$, Areo Peter Olufemi ${ }^{1}$,

\section{Email address:}

leoadeguns@gmail.com (Adegun P. T.), bjobam@hotmail.com (Bamidele J. O.), areolafemoris@yahoo.co.uk (Areo P. O.), oladimeji_ajayi@yahoo.com (Ajayi A. O.), lifecareado@gmail.com (Ajayi E. A.)

\section{To cite this article:}

Adegun Patrick Temi, Bamidele James Olusegun, Areo Peter Olufemi, Ajayi Akande Oladimeji, Ajayi Ebenezer Adekunle. Prevalence of External Genital Abnormalities among Secondary School Pupils in Ekiti State, Nigeria. American Journal of Health Research.

Vol. 2, No. 3, 2014, pp. 97-101. doi: 10.11648/j.ajhr.20140203.14

\begin{abstract}
BACKGROUND/OBJECTIVE OF THE STUDY: There is paucity of information on the prevalence of external genital abnormalities in Nigeria particularly in Ekiti State. This study was designed to determine the prevalence of external genital abnormalities among primary school pupils in Ekiti State. Patients and Methods: This was a descriptive, cross sectional study that used multistage sampling to select pupils in Primary schools in the three senatorial district of Ekiti state. Pupils from ages two to sixteen years were examined by trained physicians for external genital abnormalities. Results: A total of 1200 pupils were examined, out of which 372 [31\%] pupils had external genital abnormalities. M: $\mathrm{F}=1$. There were 31 [2.58\%] pupils with congenital external genital abnormalities out of 1200 pupils. All were males, with a prevalence of $5.18 \%$ among the boys. The prevalence of congenital external abnormalities by senatorial district was $3.43 \%$, $1.07 \%$, and $10.63 \%$ for Ekiti Central, North and South respectively. Right testicular volume was significantly greater than the left testis [ $\mathrm{t}=3.426$, P-value $=0.001]$. A high prevalence [56.15\%] of Female Genital Cutting [FGC] was noted with the highest prevalence in Ekiti South senatorial district. Conclusion: Prevalence of Congenital external genital abnormalities is still low in this environment but the prevalence of FGC is quite high. Hydrocele, micro testis and high rising testes are the commonest congenital defects.
\end{abstract}

Keywords: External Genital, Abnormalities, Prevalence, Primary School Pupils, Nigeria

\section{Introduction}

Since the 1960 s, a general surveillance has been carried out monitoring the appearance of congenital anomalies in various populations around the world ${ }^{1}$. Worldwide surveys have shown that the birth prevalence of congenital anomalies varies greatly from country to country ${ }^{2-4}$. It is reported to be as low as $1.07 \%$ in Japan and as high as $4.3 \%$ in Taiwan3. In the US, however most researches have been conducted on this subject, a $2-3 \%$ birth prevalence of congenital anomalies has been reported. The birth prevalence of congenital anomalies in England is 2\% and in South Africa it is $1.49 \%{ }^{4}$. These variations may be explained by social, racial, ecological, and economical influences ${ }^{3,4}$.

A study that investigated the number of all infants born in one year with a congenital anomaly at 22 university hospitals in Turkey found a birth prevalence of congenital anomalies of $3.65 \% \%^{5}$. Anomalies of the central nervous system were the most common defect (31\%), followed by cleft palate/lip (19\%), musculoskeletal system anomalies $(14 \%)$, and chromosomal anomalies $(13 \%)^{6}$.

In an 11-year retrospective study of records in Bahrain, a live birth prevalence of congenital anomalies of $2.7 \%$ was found. Among the anomalies, the musculoskeletal system had the highest prevalence (2.28 per 1000), followed by those affecting the genitourinary system (2.13 per 1000), while the prevalence of chromosomal disorder was 0.9 per $1000^{7}$.

A study on the prevalence of congenital external genital abnormalities in Enugu State- Nigeria got a prevalence of 0.68 per $1000^{8}$. A prevalence of $7.14 \%$ for genito-urinary 
system was reported in Ilorin - North Central region of Nigeria ${ }^{9}$.

In a third World environment like Nigeria, most deliveries occur outside the hospital setting and most circumcisions are done by traditional birth attendants. Since most of the available data on the prevalence of genital abnormalities are hospital based, they are unreliable in measuring the true prevalence of such abnormalities in the community. Hence, a special method of approach of collecting data on external genital abnormalities from the community is needed to produce a reliable result ${ }^{8}$.

It was on this basis of paucity of information especially in our environment that this study on external genital abnormalities among pupils in Ekiti State Primary Schools was undertaken.

These data will assist policy makers in planning, monitoring and evaluating programmes affecting people with these abnormalities.

\section{Methodology}

\subsection{Study Location}

The study was carried out in Ekiti State, South West Nigeria. The state is divided into 16 local government areas which are further grouped into three senatorial districts. The state was created in 1996 from the old Ondo state. It prides itself as the most culturally homogenous state in Nigeria. It is generally believed to be the most literate state in Nigeria. Hence, it's former appellation as the 'fountain of knowledge' now 'a land of honour'.

\subsection{Study Population}

The study population included the pupils of public and private primary schools across the state. The estimated total population of the pupils was put at 161,750 as at the time the study was carried out as obtained from the State Universal Basic Education Board and association of proprietors of private nursery and primary schools in the State.

\subsection{Study Design}

The study design was a descriptive, cross-sectional study.

\subsection{Sample Size Determination}

The sample size was calculated using the Fitzer's formula when population is greater than $10,000{ }^{10}$.

Using the formula the minimum sample size was 385 . However, to improve the accuracy of the study and in order to make the finding more representatives, the sample size was increased to 1200 .

\subsection{Sampling Technique}

Multistage sampling technique was used for this study. Equal samples were taken from each of the three senatorial districts (i.e. four hundred from each). From each of the senatorial districts, one Local Governments Area was selected by simple random sampling. From each of the selected Local Government Area, four hundred pupils were selected by simple random sampling using the list of the pupils in the school register as provided by the headmaster of the primary schools.

\subsection{Data Collection}

Three methods of data collection were used:

(i) Physical examination of the pupils by trained physicians [male to male and female to female pupil] and proper recording of the findings using a standard format for all the schools.

(ii) Orchidometer manufactured by "Accurate surgical and scientific instruments corporation, 3000 Shames drive, Westbury, NY 11590[RA-125plus]" was used to measure the size of each testis.

(iii) Interviewer-Administered Questionnaires were administered by trained staff on all the participants.

\subsection{Ethical Consideration}

Consent was obtained from the State Universal Basic Education Board and the association of proprietors of Private Primary Schools in Ekiti State. Consent was obtained also from the Parents Teachers Association of the selected schools.

Approval was obtained from the Ethical committee of the Ekiti State University teaching Hospital, Ado-Ekiti.

\subsection{Data Processing, Analysis and Presentation}

The questionnaires were analyzed using SPSS software version 19 and Microsoft excels 2007. Data were presented in tables, charts and summarized using simple percentages. Student's $t$ test was used to test the mean of non-categorical variables. $P$ value of less than or equal to 0.05 was taken as significant.

\section{Results}

Table 1. Age distribution of pupils in years.

\begin{tabular}{ccc}
\hline Age (yrs) & Frequency & Prevalence (\%) \\
\hline 2 & 8 & .7 \\
4 & 1 & .1 \\
5 & 15 & 1.3 \\
6 & 58 & 4.8 \\
7 & 96 & 8.0 \\
8 & 166 & 13.8 \\
9 & 172 & 14.3 \\
10 & 230 & 19.2 \\
11 & 94 & 7.8 \\
12 & 167 & 13.9 \\
13 & 132 & 11.0 \\
14 & 32 & 2.7 \\
15 & 25 & 2.1 \\
16 & 4 & .3 \\
Total: & 1200 & 100.0 \\
\hline
\end{tabular}


A total of one thousand and two hundred pupils participated in all. The males were a total of five hundred and ninety-eight (598), while the females were six hundred and two (602) in number.

Table 1 shows the age distribution of all the pupils examined. The minimum age was two years and maximum age was sixteen years.

Table 2 shows the age group distribution per senatorial district. At the age group 1-5years, the highest means was the males from Ekiti central senatorial district and also amongst the females in the age group 6-10years. The highest means was amongst the males from Ekiti north in the age group above ten years.
Table 2. Age group and sex distribution by senatorial district.

\begin{tabular}{lllll}
\hline \multirow{2}{*}{ Senatorial Districts } & Sex & \multicolumn{2}{c}{ Age group (year) } \\
& & Age 1-5 & Age 6-10 & Age >10 \\
\hline \multirow{2}{*}{ Ekiti Central } & $\mathrm{M}$ & $3.5(2.1)$ & $8.4(1.4)$ & $12.4(1.2)$ \\
& $\mathrm{F}$ & 0 & $8.9(1.1)$ & $12.1(.8)$ \\
Ekiti North & $\mathrm{M}$ & $2.4(.9)$ & $8.5(1.4)$ & $12.7(1.2)$ \\
& $\mathrm{F}$ & 0 & $8.5(1.3)$ & $12.3(1.2)$ \\
Ekiti South & $\mathrm{M}$ & $2(0)$ & $8.4(1.4)$ & $12.6(1.3)$ \\
& $\mathrm{F}$ & 0 & $8.4(1.3)$ & $12.3(.8)$ \\
\hline
\end{tabular}

Table 3 shows the distribution of external genital abnormalities [congenital and acquired] seen among the pupils. The prevalence rate of Female Genital Cutting was $56.15 \%$ and was highest in Ekiti south with prevalence rate of $63.21 \%$.

Table 3. External genital abnormalities detected on examination per senatorial district.

\begin{tabular}{|c|c|c|c|c|c|c|}
\hline \multirow{2}{*}{ External Genital Abnormalities } & \multicolumn{3}{|c|}{ Senatorial Districts } & \multirow[b]{2}{*}{ Ekiti South } & \multirow{2}{*}{ Popu. Sampled } & \multirow{2}{*}{ Prevalence (\%) } \\
\hline & Sex & Ekiti Central & Ekiti North & & & \\
\hline \multirow{2}{*}{ Hydrocele } & M & 0 & $1(.535 \%)$ & $10(4.83 \%)$ & 598 & 1.84 \\
\hline & $\mathrm{F}$ & 0 & 0 & 0 & 602 & 0.00 \\
\hline Unilateral High rising testis & M & $7(3.43 \%)$ & 0 & $7(3.38 \%)$ & 598 & \\
\hline Total Congenital: & & $7(3.43 \%)$ & $2(1.07 \%)$ & $22(10.63 \%)$ & 598 & 5.18 \\
\hline \multirow{2}{*}{ Post Circumcision Skin Adhesion } & M & 0 & 0 & $3(1.45 \%)$ & \multirow{2}{*}{$\begin{array}{l}598 \\
602\end{array}$} & \multirow{2}{*}{$\begin{array}{l}0.50 \\
0.00\end{array}$} \\
\hline & $\mathrm{F}$ & 0 & 0 & 0 & & \\
\hline \multirow[t]{2}{*}{ Total Defects: } & & 109 & 116 & 147 & & \\
\hline & M & 204 & 187 & 207 & & \\
\hline \multirow[t]{2}{*}{ Sampled Popu: } & $\mathrm{F}$ & 196 & 213 & 193 & \multirow{3}{*}{1200} & \multirow{3}{*}{2.58} \\
\hline & $M \& F$ & 400 & 400 & 400 & & \\
\hline Prevalence (\%)/ Districts: & & 27 & 29 & 37 & & \\
\hline
\end{tabular}

Table 4 shows the difference in testicular volume. The mean testicular volume of the right testis was greater than the left. This difference was statistically significant with $\mathrm{t}=3.426$ and $\mathrm{p}$-value $=0.001$.

Table 4. showing the mean difference in testicular volume between right and left Testes.

Paired Samples Test

\begin{tabular}{|c|c|c|c|c|c|c|c|c|c|}
\hline \multicolumn{10}{|c|}{ Paired Differences } \\
\hline & & \multirow[t]{2}{*}{ Mean } & \multirow[t]{2}{*}{ Std. Deviation } & \multirow{2}{*}{$\begin{array}{l}\text { Std. Error } \\
\text { Mean }\end{array}$} & \multicolumn{2}{|c|}{$\begin{array}{c}95 \% \text { Confidence Interval } \\
\text { of the Difference }\end{array}$} & \multirow[t]{2}{*}{$\mathrm{t}$} & \multirow[t]{2}{*}{ df } & \multirow[t]{2}{*}{ Sig. (2-tailed) } \\
\hline & & & & & Lower & Upper & & & \\
\hline Pair 1 & $\begin{array}{c}\text { Rtestes_Size_inVOLUME - } \\
\text { Ltestes Size_inVOLUME }\end{array}$ & .117 & .828 & .034 & .050 & .183 & 3.426 & 591 & .001 \\
\hline
\end{tabular}

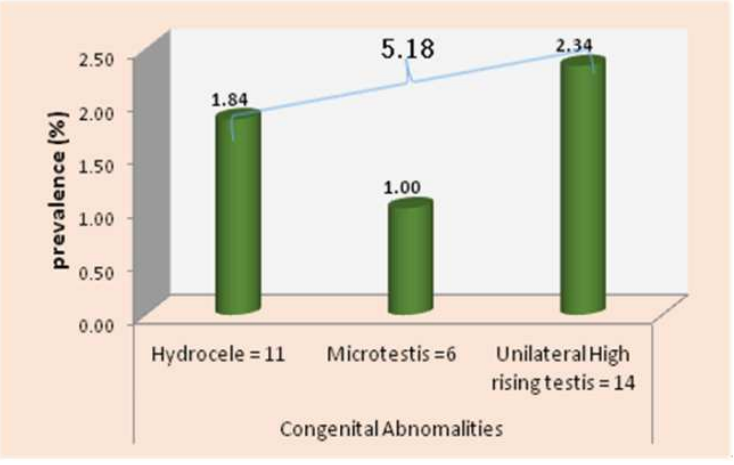

Fig 1. Prevalence of congenital abnormality among the male pupils.
Fig 1 shows the prevalence of different congenital external genital abnormalities. There were three types of abnormalities detected which were micro testis with prevalence of $1 \%$, high rising testis with prevalence of $2.34 \%$ and hydrocele with prevalence of $1.84 \%$.

The overall prevalence of external genital abnormalities is $31 \%$ and $2.58 \%$ for congenital external genital abnormalities.

Fig 2 is a bar chart showing the prevalence of circumcision per senatorial district. All males were circumcised, while Ekiti central senatorial district has the least prevalence of FGC. 


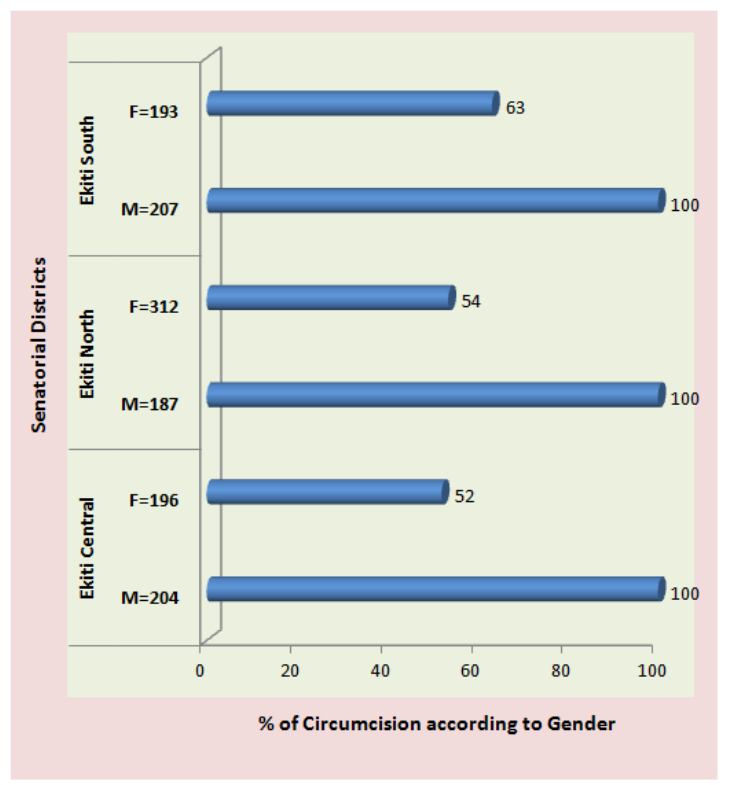

Fig 2. Bar chart showing the prevalence of circumcision per senatorial district.

\section{Discussion}

The prevalence of $2.58 \%$ of congenital genital abnormality seen in this study is less than the prevalence of $6.8 \%$ seen among secondary school children in the eastern part of Nigeria by Ozoemena et al. ${ }^{8}$ But this is higher than the prevalence of $1.4 \%$ found among the neonates at Ife by Bakare et al. ${ }^{11}$. There was no known reason for this margin of difference between the prevalence amongst the neonates and the Primary school pupils in the southwestern parts of Nigeria.

The higher prevalence of $27.8 \%$ reported in Serbian by Rajangam et al may not be unconnected with the high level of industrialization in Europe which might predispose the mother to environmental pollution ${ }^{12}$, although future research is needed to confirm this.

This study has shown that there are fewer congenital external abnormalities in this environment as compared to other parts of the country, however the high prevalence of high rising testis which is an indication of abnormal positioning of the testis may predispose to torsion or infertility later in life ${ }^{8,11}$. This is of importance because developmentally testicular descent is conceptualized into three phases: transabdominal, transinguinal and extracanalicular migration. Improper extracanalicular migration may give rise to high rising testis on the affected side. In order for normal spermatogenesis to occur, it is necessary for the testes to descend into the scrotum where there is low-temperature environment that maintains a temperature 20 to 30 lower than core body temperature ${ }^{13}$.

However, there is no obvious reason for the high prevalence of hydrocele in Ekiti south senatorial district. This requires future research for confirmation.

Furthermore, a study to show that there may be high incidence of testicular torsion and infertility in Ekiti central and south senatorial district is desirable.

It was discovered in this study that the right testicular volume was significantly higher than the left $[\mathrm{P}=0.001]$. No reason can be immediately linked to this finding. This is in variant with the study of Kuijper et al where ultrasonographic machine was used to measure the testicular volume of children from age 0 to 6years and reported no significant difference between the testes ${ }^{14}$. However, the study by Bogaert on Genital asymmetry in men reported a variation in testicular volume based on the dominant hemisphere of the participant ${ }^{15}$. A study to determine the dominant hemisphere in school pupils is a promising future research.

Surprisingly, the high prevalence of Female Genital Cutting [FGC] of $56.15 \%$ in this study is a worrisome development. This prevalence is higher than the UNICEF prevalence of $37 \%$ for Nigeria in 2001 , despite the fact that Nigeria joined other members of the 47th World Health Assembly in 1994 to resolve to eliminate $\mathrm{FGC}^{16,17}$.This is in support of the fact that there is no known scientific evidence that women who have been mutilated are more faithful or makes better wives than those who are not mutilated. Whereas the adverse consequences of mutilation are very grave and include shock from pain, hemorrhage, infection, acute urinary retention, chronic pelvic infection and gynatresia, to mention but a few ${ }^{18,19}$. This shows that awareness campaign against FGC has not sunk at the grassroots.

\section{Conclusion}

The prevalence of external genital abnormalities is $31 \%$ in this environment. However, the prevalence of congenital external genital abnormality is $2.58 \%$ with high rising testis being the most prevalent among the boys [2.34\%]. There were no congenital external genitalia seen amongst the females.

Surprisingly, a lot of female genital mutilation is still being practiced in this environment.

\section{Recommendations}

1. Pupils must be encouraged to go for medical examination once awhile to detect any external genitalia and correct defect early.

2. Campaign against FGC must be strengthened at the grassroots.

3. There is need for legislation against FGC backed by sanctions to discourage this practice.

\section{Acknowledgements}

Matron Agbelusi and Matron Adjoto SV assisted with data collection, while Mr. Inubile Joshua provided statistical advice. 


\section{References}

[1] Blomberg M, Selbing A and Kallen B [2000]. Congenital malformations in the southeast of Sweden - a registry study with validation. Acta Paediatr, 89: $1238-43$.

[2] Temtamy SA, Abdel Meguid N, Mazen I, Ismail SR, et al [1998]. A genetic epidemiological study of malformations at birth in Egypt. East. Mediterr. Health J, 4:252 - 59.

[3] Shi LM, Chia SE, Chan OY, Chew SK, et al [2002]. Prevalence of birth defects and parental work in Singapore live births from 1994 to 1998: a population-based study. Occup. Med, 52: 325 - 31 .

[4] Biri A, Onan A, Korucuoglu U, Tiras B. et al [2005]. Birth prevalence and distribution of congenital anomalies in a university hospital. Perinatobilek E, Boduroglu $\mathrm{K}$ and Alikasifoglu Ml. Dergisi, 13: 86 - 90.

[5] Tuncbilek E, Boduroglu K and Alikasifoglu M [1999]. Results of the Turkish congenital malformation survey. Turk. J. Pediatr, 41: 287-97.

[6] Tomatir AG, Demirhan H, Sorkun HC, Koksal A, et al [2009]. Major congenital anomalies: a five-year retrospective regional study in turkey. Genetic and Molecular Research, 8 (1) $19-27$.

[7] Al Arrayed SS [1995]. Epidemiology of congenital abnormalities in Bahrain. East. Mediterr. Health J. 1, 248-52.

[8] Ozoemena OF, Mbah AU [2007]. The prevalence pattern of external male genital defects among secondary school students in Enugu State of Nigeria. Niger J Clin Pract, 10(2): $120-5$

[9] Odelowo EO, Adedoyin MA, Anjorin AS, Fakeye OO [1991]. Pattern of Congenital malformations in Nigeria children -Int surg., Jan - Mar 76(1):43 -8

[10] Araoye MO.Subjection and sample size determination. In: Research Methodology with Statistics for Health and Social Sciences. 1sth eds.Nathadex publishers,Ilorin,Nigeria.2003; 115-120.

[11] Bakare TIB,Sowande OA,Adejuyigbe OO,Chinda JY,Usang UE [2009]. Epid of ext birth defects in neonates in southwest,Nigeria.African J Paed surg, 6(1):28-30.

[12] Rajangam S, Devi R [2007]. Consanguinity and chromosomal abnormality in mental retardation and a multiple congenial anomaly. J. Anat Soc India, 56(2): 30 -33.

[13] Elder JS [1992]. Abnormalities of the genitalia in boys and their surgical management. In: Walsh PC,Retic AB, Wein AJ, Vaughan ED (eds): Campbell's urology,8th ed. Philadephia,WB Saunders, 2334-52.

[14] Kuijper EAM,Vankooten J, Verbeke JIML, Van Rooijen M, Lambalk CB [2008]. Ultrasonographically measured testicular volumes in 0-to 6-year-old boys. Human Reproduction, 23(4): 792-96.

[15] Bogaert AF [1997]. Genital asymmetry in men. Human reproduction, 12(1): 68-72.

[16] UNICEF [2001]. Children and Women's right in Nigeria: A wake up call. Situation assessment and analysis,harmful traditional practice(FGM) Abuja NPC and UNICEF Nigeria, 195-200.

[17] Ibekwe PC, Onoh RC, Onyebuchi AK, Ezeonu PO, Ibekwe RO [2012]. Female genital mutilation in south east,Nigeria : A survey on the current knowledge and practice. J Pub.Health Epidemiol, 45(5): 117-22.

[18] Okeke TC,Anyaehie USB,Ezenyeaku CCK[2012]. An overview of Genital mutilation in Nigeria, 2(1):70-73.

[19] Verzin JA[1975]. Sequelae of female circumcision. Trop Doct, 5:163-9. 